InterAção | 59

\title{
CORRUPÇÃO E INVESTIMENTO ESTRANGEIRO DIRETO
}

\author{
Luciano Vaz Ferreira ${ }^{1}$
}

Fabio Costa Morosini²

\section{Resumo}

A presente pesquisa possui como problema central de investigação a análise do impacto da corrupção no fluxo de investimento estrangeiro direto (IED). A primeira parte da pesquisa estuda o papel do IED na economia globalizada; a segunda tem como objetivo analisar as consequências da corrupção em operações envolvendo IED. Para tanto, realizou-se uma revisão bibliográfica sobre o tema. A etapa da investigação aponta que a percepção da corrupção pode ser um fator condicionante para o ingresso de IED em um determinado país.

Palavras-chave: Globalização. Corrupção. Investimento Estrangeiro Direto. Instituições.

\section{Abstract}

This research aims to analyze the impact of corruption in the flow of foreign direct investment (FDI). The first part of the research

1 Doutorando em Estudos Estratégicos Internacionais (UFRGS). E-mail: Ivazferreira@ gmail.com.

2 Doutor em Direito (University of Texas atAustin), Professor do Programa de Pós-Graduação em Estudos Estratégicos Internacionais (UFRGS). E-mail: fabio.morosini@ufrgs.br. 
60 | InterAção

studies the role of FDI in the global economy; the second examines the consequences of corruption in transactions involving FDI. For this purpose, we carried out a bibliographic review on the subject. The stage of the research indicates that the perception of corruption can be a conditioning factor for the inflow of FDI in a particular country.

Keywords: Globalization. Corruption. Foreign Direct Investment. Institutions.

\section{INTRODUÇÃO}

A globalização traz novas possibilidades de desenvolvimento, graças ao estabelecimento de um intenso fluxo de capitais. No mundo global, a estratégia dos países é de beneficiarem-se com o investimento estrangeiro direto (IED) ao mesmo tempo em que lançam suas empresas transnacionais em novos mercados.

Um dos grandes problemas do mundo globalizado é o fenômeno da corrupção. Alimentada pelo setor privado e frequente nas práticas de investimento estrangeiro, a corrupção posa como uma verdadeira ameaça para a dinâmica do livre mercado. Nesse contexto, o presente trabalho possui como objetivo analisar a possível influência da corrupção na atração do IED.

Como metodologia, optou-se por fazer revisão bibliográfica. As fontes possuem natureza interdisciplinar, com trabalhos oriundos das ciências jurídicas, econômicas e administrativas.

$\mathrm{O}$ artigo é dividido em duas partes. A primeira parte refere-se ao papel que o IED desempenha no sistema econômico mundial 
InterAção | 61

contemporâneo, inserido em um cenário globalizado. Para isso, é necessário definir conceitualmente o IED, diferenciando-o dos demais tipos de investimentos. Também será referida, nesse ponto, a importância que as instituições possuem para a escolha do Estado hospedeiro de investimento. A segunda parte é dedicada para entender as consequências da corrupção no fluxo de IED. Para isso, serão analisadas, primeiramente, as definições de corrupção indicadas pelos autores. Após, será investigada a possibilidade de influência do fenômeno na atratividade de IED pelos países.

\section{Os Fluxos Internacionais de Investimento Estrangeiro Direito}

A expansão do capitalismo e o impacto das novas tecnologias, especialmente na esfera do transporte e das comunicações, criaram condições para a globalização, fenômeno distinto de outros processos internacionalizantes do passado ${ }^{3}$. A revolução tecnológica foi responsável pelo encurtamento das distâncias naturais de tempo e de espaço, que conduziu a um cenário de crescente integração e interdependência mundial, em diferentes áreas. Construiu-se, assim, uma densa rede de relações que perpassam a vetusta figura do Estado. Nesse contexto, a globalização pode ser caracterizada como a tomada de

3 Entende-se que as grandes navegações e as primeiras expressões do capitalismo já representavam de certa forma, um movimento de crescente integração entre diferentes zonas do mundo. ARRIGHI (1998) aponta o sistema econômico da cidade-estado de Gênova, do Século XV, uma expressão primária do capitalismo, como um processo baseado na extraterritorialidade. No entanto, se os antigos processos apresentavam limitações de alcance, a globalização apresenta-se como um processo muito mais abrangente, por que engloba todas as partes do mundo. 
consciência de interesses comuns a tudo aquilo que recobre a superfície da terra (ARNAUD, 1999, p. 4).

O processo alterou drasticamente a dinâmica da economia, que passou a ter como base um intenso fluxo transnacional de bens, serviços e capitais. Entende-se que a adoção dominante dos princípios do livre comércio criou um verdadeiro "mercado global", independente de fronteiras geográficas ou políticas. Teoricamente, o livre trânsito dos recursos permite que eles sejam eficientemente alocados e melhor aproveitados, de acordo com as especificidades e capacidades de cada região, fomentando-se, assim, o desenvolvimento das nações como um todo ${ }^{4}$.

A redução das barreiras comerciais, efetuada por meio da institucionalização de um sistema de negociações multilaterais (Acordo Geral de Tarifas e Comércio e depois Organização Mundial do Comércio), fez com que o comércio adquirisse proporções mundiais. Desde então, é possível exportar ou importar produtos e serviços de praticamente qualquer parte do mundo. Hoje, o comércio internacional explora um novo estágio, proporcionado pelo contexto globalizante. Sustenta o livre trânsito internacional de capitais, que de maneira fluida, supera as limitações físicas do comércio tradicional. A ideia é que o capital abundante dos países desenvolvidos, ávidos por novos mercados, seja direcionado a países em desenvolvimento, carentes de investimentos, o que geraria crescimento econômico e redução de desigualdades.

O "investimento estrangeiro" pode ser conceituado como a

40 fundamento é a "Teoria das Vantagens Comparativas" de David Ricardo, descrita em sua obra "Princípios de Economia Política e Tributação" de 1817. 
"transferência de fundos ou materiais de um Estado (chamado de 'país exportador de capital') para outro (chamado de 'país receptor') em troca de uma participação direta ou indireta no empreendimento" (SORNARAJAH, 2010, p. 08). Enquadrariam nessa definição, por exemplo, empresas que deixam de apenas produzir em seu solo e exportar para exterior e passam a desenvolver operações envolvendo o emprego de capital. Sendo assim, pulverizam a sua produção e sua logística ao redor do globo; estabelecem filiais e subsidiárias; engajam-se em atividades de joint ventures com empresas locais, tudo em busca da maximização da eficiência econômica. $\mathrm{O}$ modelo representativo dessa nova era é a estrutura empresária de caráter multinacional (ou transnacional): empresas que exploram a sua atividade econômica além de seu país de origem e organizam o seu sistema de produção e suas estratégias de acesso a consumidores em escala mundial.

Costuma-se a dividir o investimento estrangeiro em duas áreas: investimento estrangeiro de portfólio e investimento estrangeiro direto.

O investimento estrangeiro de portfólio é representado pelo movimento de dinheiro com o propósito de compra de ações em empresas localizadas em outros países, sem se vincular a sua gestão (SORNARAJAH, 2010, p. 08). É conhecido como “capital especulativo", pois objetiva ganhos de curto prazo, migrando de mercado facilmente.

De acordo com a definição do Banco Mundial e do Fundo Monetário Internacional (FMI), o investimento estrangeiro direto (IED) ocorre quando é mantida participação societária duradoura na gestão de empreendimento em economia diversa do investidor. É 
64 | InterAção

necessário que o investidor possua $10 \%$ ou mais do capital votante. Conforme o World Economic Survey 2005 (UNITED NATIONS, 2005, p. 79), o IED divide-se em projetos de investimento originais (greenfield investment), quando o investidor estrangeiro inaugura um novo empreendimento, e fusões e aquisições transfronteiriças (cross-border merger and acquisitions), quando o investidor compra ou realiza fusão com empreendimento nacional já existente.

Ainda que parte da literatura especializada veja o fenômeno do IED como representação de uma agenda neoliberal para garantir os interesses econômicos das nações desenvolvidas, conduzindo à submissão das economias em desenvolvimento às atividades das empresas multinacionais (SORNARAJAH, 2010, p. 53-55), estudos apontam que o relacionamento pode ser benéfico para o Estado receptor caso consiga atrair e manter bons investimentos. Neste contexto, alguns aspectos positivos sobre o ingresso de IED podem ser indicados, especialmente em relação aos países emergentes enquanto hospedeiros.

Entende-se que a liberalização do investimento incrementa a competitividade internacional entre as empresas, produzindo um aumento na qualidade dos produtos e serviços oferecidos. Pensa-se em uma empresa nacional que sofre com a concorrência de uma companhia transnacional do mesmo ramo que produz mais eficientemente (produto mais barato e de melhor qualidade, por exemplo). Assim, o ambiente competitivo internacional servirá de estímulo para que os produtores locais busquem novas estratégias. $\mathrm{O}$ inverso também é possível acontecer: caso revelem-se empreendimentos de sucesso, as empresas locais podem acessar os mercados de outros países. 
O investidor estrangeiro direto geralmente introduz tecnologia, know-how e práticas de excelência gerencial que inexistem na economia hospedeira (SORNARAJAH, 2010, p. 48). Nesse passo, conforme relatório da Organização para a Cooperação e Desenvolvimento Econômico (OCDE) (2002, p. 05), o IED pode ajudar nas condições ambientais e sociais do Estado receptor, como por exemplo, transferindo tecnologias "mais limpas" (que causam menos danos ao meio ambiente) e levando a implementação de políticas corporativas voltadas à responsabilidade social.

Outro ponto interessante é o desenvolvimento de infraestrutura nacional graças ao ingresso do IED. O incremento em infraestrutura de transporte, saúde e educação, por exemplo, não só facilitam que o investidor estrangeiro conduza o seu empreendimento como também beneficiam a sociedade do país receptor como um todo (SORNARAJAH, 2010, p. 48).

Estudos apontam um aumento vertiginoso no uso de IED em negócios internacionais, o que demonstra a sua importância para a economia mundial na atualidade. A partir da década de 90, com a abertura de novos mercados nacionais e a onda de privatizações, houve um rápido crescimento do IED e da participação das empresas transnacionais (UNITED NATIONS, 2005, p. 79). Indicadores do Banco Mundial mencionam que em 20 anos, o dinheiro investido de maneira internacional aumentou de aproximadamente 200 milhões em 1990 para quase 1,3 trilhão de dólares em 2010.

A partir disso, observa-se que a maioria de nações procedeu à liberação do IED e a consequente reforma de seus marcos regulatórios na área, de modo a tornar suas economias mais atrativas a in- 
66 | InterAção

vestidores (WORLD COMISSION ON THE SOCIAL DIMENSION OF GLOBALIZATION, 2004, p. 28). Instaurou-se, assim, um interessante ambiente de competitividade entre os Estados pelo recebimento de IED, todos visando extrair a maior quantidade de benefícios desse fenômeno econômico.

As vantagens competitivas para a atração de projetos de IED podem ser representadas por diversos elementos. Conforme MUDAMBI e NAVARRA (2002, p. 635), características macroeconômicas como tamanho e crescimento do mercado, disponibilidade de trabalho e seus custos, níveis de inflação e endividamento externo e a situação do balanço de pagamentos são tradicionalmente considerados como indicadores para o grau de atratividade de IED. No pensamento contemporâneo, além desses fatores, cresce a ideia de que as estruturas institucionais nacionais são peças fundamentais para a determinação dos fluxos de IED.

Sob o ponto de vista econômico, NORTH (1991, p. 97) conceitua as instituições como restrições a conduta humana desenvolvidas para estruturar as interações políticas, econômicas e sociais da vida em sociedade. Consistem em restrições informais (como costumes e códigos de condutas) e regras formais (como o sistema jurídico). $\mathrm{O}$ comportamento egoístico e utilitarista dos agentes econômicos, que buscam a maximização dos benefícios e minimização dos prejuízos, produz um cenário de incertezas, que pode acarretar a elevação dos custos de transação. Nessa linha teórica, entende-se que o estabelecimento de instituições produz maior certeza às interações sociais; os agentes conhecerão as regras que regulam o seu comportamento e serão capazes de calcular os seus riscos e os custos de transação envol- 
vidos, de modo a reduzi-los. Sendo assim, pode-se dizer que a qualidade das instituições impacta na formação dos custos de transação, fazendo com que o comportamento e escolha dos atores sociais sejam influenciados pela configuração da estrutura institucional.

Sobre a relação entre instituições e comportamento dos agentes, COOTER e SCHÄFER (2006, p. 03) apresentam como exemplo a produção das pesquisas em inovação e tecnologia, que se baseiam em uma relação simbiôntica entre investidor e inovador; enquanto o primeiro investe, esperando retorno financeiro, o segundo cria, esperando o investimento. Essa troca é baseada em uma dinâmica de (des)confiança recíproca: o inovador precisa confiar que o investidor não disseminará a ideia, e este deve confiar que o investidor não se apropriará do capital. Um ambiente institucional que preveja um direito de propriedade intelectual garante a confiança mútua; caso esse arcabouço jurídico inexista, os investidores irão investir menos, enquanto os inovadores irão ficar com receio que seu trabalho seja copiado indevidamente. Essa situação conduziria à inibição do investimento nessa área.

Em um cenário globalizado de competitividade entre as nações e grande mobilidade de empresas e de fatores de produção, os investidores estrangeiros irão decidir pelo melhor ambiente institucional para o seu empreendimento, que ofereça baixos custos de transação, alta produtividade e retorno financeiro garantido. Nesse passo, os custos de transação relacionados ao sistema legal, político e administrativo podem determinar a opção por um ou outro país receptor na definição do local de investimento (AMAL; SEABRA, 2007, p. 235). 
68 | InterAção

Conforme MUDAMBI E NAVARRA (2002, p. 641), as instabilidades do ambiente institucional geram incertezas às operações de IED, aumentando o custo do empreendimento e desencorajando sua entrada. Na mesma linha, BÉNASSY-QUÉRÉ, COUPET e MAYER (2005, p. 765) apontam que a ineficiência do governo, mudanças políticas, fraca proteção dos direitos de propriedade e do cumprimento do direito em geral contribuem para essa incerteza. Os argumentos são no sentido de que os investidores seriam mais propensos a entrar em países onde o cumprimento do regime (político e jurídico) é relativamente mais fácil de prever (MUDAMBI; NAVARRA, 2002, p. 641).

Existem sólidas pesquisas empíricas que defendem a existência de relação entre a movimentação de investimentos e a qualidade das instituições do país hospedeiro. Ao realizarem o cruzamento de índices de governança e fluxos de IED ${ }^{5}$, DAUDE e STEIN (2007, p. 341) afirmaram que "a qualidade das instituições possui efeitos positivos sobre o IED", de modo que o "impacto de variáveis institucionais é estatisticamente significativa e economicamente muito

5 GLOBERMAN e SHAPIRO pesquisaram os dados referentes a 144 países entre 1995 e 1997. Para os fluxos de investimento, foram utilizados os relatórios da United Nations Conference on Trade and Development (UNCTAD). Em relação aos aspectos institucionais, os autores utilizam os Worldwide Governance Indicators (Indicadores Mundiais de Governança), desenvolvido por KAUFMANN, KRAAY e ZOIDO-LOBATÓN (1999) e adotado pelo Banco Mundial. Trata-se de um conjunto de pesquisas realizadas com vários segmentos da sociedade ao redor do mundo. 0 instrumento é dividido em seis dimensões: voz e accountability, estabilidade política e ausência de violência, efetividade do governo, qualidade regulatória, aplicação do direito (rule of law) e controle da corrupção. Para acessar os índices, consultar: http://info.worldbank.org/ governance/wgi/index.asp. 
InterAção | 69

importante". Entendimento similar pode ser encontrado nos estudos de GLOBERMAN e SHAPIRO (2002, p. 1914-1916) e de LI e RESNICK (2003, p. 202-203). DUNNING e LUNDAN (2008, p. 314) ao analisarem as pesquisas citadas concluíram que a "boa governança ajuda a atrair o IED, enquanto a má governança repele".

Alguns exemplos podem ajudar a ilustrar o argumento. A existência de uma legislação nacional que proíbe a expropriação imotivada de IED confere maior tranquilidade ao investidor, que poderá calcular, de maneira mais precisa, os riscos que envolvem o seu projeto. Ainda, a proteção da propriedade intelectual pelo direito do hospedeiro pode contribuir para a atração de IED ligado ao desenvolvimento tecnológico. Nessa mesma linha, uma nação marcada pela instabilidade política e com histórico de nacionalização de IED, por sua vez, poderá repelir investidores, que se demonstrariam cautelosos em aplicar seus recursos em um local de retorno financeiro incerto.

\section{As Consequências da Corrupção no Investimento Estrangeiro Direto}

Nas análises de risco e qualidade institucional realizadas pelos investidores estrangeiros, tem-se adicionado o grau de corrupção no país hospedeiro como um dos elementos que auxiliam a definição do local do investimento. Cresce, nos últimos anos, pesquisas que buscam correlação entre IED e o fenômeno da corrupção.

É importante, antes de adentrar nos pormenores envolvendo o problema de pesquisa, encontrar uma definição de corrupção. $\mathrm{O}$ BANCO MUNDIAL (1997, p. 08) costuma conceituar a corrupção como sendo o "abuso de cargo público para obter benefícios privados". 
70 | InterAção

Como pode ser observado, o conceito é amplo e englobaria uma série de condutas. A mais evidente é a prática de suborno, no qual incidem tanto o funcionário público que exige, solicita ou recebe vantagem indevida, como os agentes privados que pagam esses valores para terem algum benefício do poder público. Situações que não envolvem suborno também estariam incluídas na definição, como a patronagem e o desvio e apropriação de recursos públicos.

Um conceito um pouco diferente é apresentado pela ONG TRANSPARENCY INTERNATIONAL (2008, p. 02) que entende a corrupção como o "abuso de poder confiado para obter benefícios privados". Constata-se que não há menção ao termo "cargo público". A ideia é defender a possibilidade de prática corrupta envolvendo apenas atores privados (“corrupção privada ou corporativa”). Um exemplo seria a conduta de um executivo de uma grande multinacional que mascara a péssima saúde financeira da empresa e emite bônus em seu benefício e de seus colegas, enganando os interesses dos acionistas e investidores.

Estudos apontam a relação entre a percepção de corrupção de um país e sua capacidade de atrair investimento estrangeiro. Os argumentos são no sentido de que um país visto como corrupto pode sofrer inibição ou fuga de IED (WEI, 2001, p. 02-03). Outra possibilidade é a atração de IED de baixa qualidade, com pouco volume de capital e sem perspectivas de transferência de tecnologia.

Existem explicações para esse comportamento dos investidores estrangeiros. Consoante pesquisa desenvolvida por MAURO (1995, p. 705-706 e 1997, p. 104), a corrupção contribui para a insta- 
InterAção | 71

bilidade política, baixo crescimento econômico, diminuição do investimento doméstico e o uso dos gastos públicos de maneira ineficiente, elementos que interferem na qualidade das instituições nacionais. Assim, fazendo uma conexão com o que foi apresentado na primeira parte, pressupõe-se que os investidores de IED farão uma avaliação das instituições dos países receptores, buscando por aqueles que possuam mecanismos institucionais de natureza política e jurídica que possam minimizar a incidência da corrupção e, consequentemente, dos custos de transação.

Sobre os custos de transação envolvidos, não se pode esquecer que o IED é um investimento de grande vulto e de tempo longo para o retorno financeiro, de modo que é necessário planejamento de todas as variáveis capazes de interferir no sucesso econômico do empreendimento. Nesse passo, conforme SHLEIFER e VISHNY (1993, p. 612), WEI (2001, p. 03), e TANZI (1998, p. 586) a corrupção é vista como uma espécie de "tributação extra" que inibe os IEDs. O suborno sistematicamente exigido por uma autoridade pública; a necessidade de contratação de lobistas para a concessão de licenças e outros benefícios; os riscos de perder o empreendimento em caso de crise institucional: tudo é traduzido como custo para atividade empresária nos projetos de IED.

Algumas pesquisas empíricas têm sido conduzidas para comprovar a existência de relações entre o fenômeno da corrupção e o ingresso de IED, destacando-se os trabalhos de WEI (2000a, 2000b, 2001) e HABIB e ZURAWICKI (2001).

WEI (2000a, p. 03) analisou os fluxos de investimento originados de 12 países em direção a 45 hospedeiros, cruzando-os com 
indicativos de percepção da corrupção ${ }^{6}$. A conclusão do autor foi no sentido de que o acréscimo do nível de corrupção em um país opera efeitos similares ao aumento da carga tributária em um Estado hospedeiro. Para o autor (WEI, 2000a, p. 08), o aumento do nível nacional de corrupção de baixo para alto (como na situação de um índice de corrupção igual à Singapura para um índice apresentado pelo México) equivale a aumentar entre $18 \%$ a $50 \%$ a tributação de um país. Levando em consideração a necessidade que a globalização impõe de redução das barreiras comerciais e tributárias, trata-se de uma elevação brutal do custo para manter uma atividade empresarial, situação que, obviamente, prejudica o país.

Em estudo similar, HABIB e ZURAWICKI (2001, p. 691698) analisaram o ingresso de IED em 111 países durante o período de 1994-1998 relacionando-o com os respectivos índices de percepção de corrupção ${ }^{7}$. O resultado também aponta para a existência de uma interferência negativa da corrupção na atração de IED. Os autores ponderam que a corrupção deve ser analisada em conjunto com ou-

6 0s índices de percepção de corrupção tentam representar como a comunidade internacional vê a incidência do fenômeno em um determinado país. Esses índices são compostos por várias pesquisas e entrevistas realizadas por instituições respeitáveis, refletindo a opinião de observadores de todo o mundo, como especialistas no assunto, analistas de risco e empresários, incluindo pessoas que vivem e trabalham nos países avaliados. Os dados são retirados de instituições internacionais que estudam o desenvolvimento econômico, empresas de análise econômica e de risco, ONGs de pesquisa em democracia e governança e instituições acadêmicas. Wei utilizou, em sua pesquisa, os índices calculados por duas agências de avaliação de riscos de investimento (Economist Intelligence Unit e a PRS Group) e uma organização não governamental (Transparency International).

7 Também foram utilizadas as pesquisas do PRS Group e da Transparency International. 
tras variáveis que caracterizam o ambiente social, pois seus efeitos serão menores na presença de fatores positivos de atratividade de IED, como a abertura de mercado e estabilidade política. Concluem que a corrupção é uma "barreira, e não um fator decisivo, para a realização do pleno potencial de investimento de um país".

Outra constatação interessante diz respeito a possível influência da corrupção no tipo de investimento estrangeiro. Conforme dados levantados por WEI (2000b, p. 14), países com altas taxas de corrupção possuem baixo IED comparativamente em relação aos investimentos de portfólio. Isso ocorre por que esse tipo de investimento é menos dependente do arranjo político-institucional para florescer. Enquanto as operações de IED são vulneráveis à extorsão de agentes governamentais, uma vez que necessitam firmar um relacionamento duradouro com o poder público, na forma de concessão de autorizações, licenças e benefícios, o investimento de portfólio desenvolve pouco contato com o governo, pois é um projeto de retorno financeiro em curto prazo e de fácil mobilidade para outras economias.

Outras pesquisas, realizadas na forma de entrevistas, auxiliam a comprovação dos argumentos apresentados. Em estudo da TRANSPARENCY INTERNATIONAL (2009, p. 21), no qual foram entrevistados 2.700 executivos oriundos de 26 países, um a cada quatro respondentes indicou que a corrupção prejudica a operação e o crescimento de seu negócio. Dentre 350 executivos seniores entrevistados pela PRICEWATERHOUSECOOPERS ( $\left.{ }_{w} C\right)$ (2008, p. 02) quase $45 \%$ dos entrevistados confessou que costuma desistir de ingressar em um mercado ou implementar um negócio devido ao risco de corrupção. Por fim, conforme pesquisa de WEITZEL 
74 | InterAção

e BERNS (2006, p. 01), em análise de quase cinco mil operações de fusão e aquisição envolvendo IED, revelou-se que ambientes com alto índice de corrupção reduzem a avaliação das empresas nacionais, tornando-as menos atrativas para investidores.

Entende-se, no entanto, que a relação entre corrupção e o baixo nível não deve ser encarada como uma espécie de fórmula matemática. Existem casos emblemáticos de países que são classificados como corruptos, mas costumam a receber grande quantidade de investimento, como China, Rússia e Angola. Tal situação demonstra que o ambiente institucional (pouco ou baixa corrupção) pode ser uma condicionante para a definição do ingresso de IED, mas não é a única variável existente (HABIB e ZURAWICKI, 2001, p. 698). Cogita-se que os fatores macroeconômicos (como o tamanho do mercado, custo da mão de obra, etc.) extraordinários acabaram sendo avaliados como mais importantes para os estrangeiros que investem nesses países.

Contudo, autores apontam que mesmo os países que apresentam grandes taxas de ingresso de IED e um ambiente corrupto podem ter problemas no futuro. Segundo ROSE-ACKERMAN (1997, p. 33), na medida em que essas sociedades com deficiências institucionais de transparência despontam economicamente, o risco de aumento vertiginoso da corrupção e de uma consequente espiral de declínio econômico é enorme: pensa-se na profusão de projetos de infraestrutura superfaturados, ou o fácil desvio de novos recursos que se encontram em abundância. De maneira complementar ao argumento, WEI (2001, p. 03) estima que a China teria o dobro de IED se combatesse de maneira mais eficiente a corrupção.

Ainda, não se pode esquecer que o valor nominal da quanti- 
InterAção | 75

dade de ingresso de IED, demonstrado nos relatórios, não é suficiente para atestar a qualidade do investimento recebido. Tomando por base os escritos de SHLEIFER e VISHNY (1993, p. 615), observa-se que os governos de países com alta incidência de corrupção possuem a tendência de direcionar os investimentos a projetos que facilitem a ocultação das práticas corruptas e potencializem os ganhos pessoais dos agentes. Isso pode ser demonstrado pela preferência por projetos de alta complexidade, custo elevado e fornecedores monopolistas, como os investimentos em infraestrutura e na área de defesa. O risco de canalização de recursos nacionais e estrangeiros para obras de escassa utilidade social é alto, o que pode acarretar graves prejuízos no desenvolvimento do país em longo prazo ${ }^{8}$.

Constatada a possibilidade de a corrupção ser uma condicionante para o ingresso de IED, questionam-se quais estratégias os países podem tomar para enfrentar o problema. A saída pode ser a implementação de uma política de controle da corrupção. $\mathrm{O}$ objetivo é estabelecer instituições nacionais que garantam que os investidores não terão seus empreendimentos assediados por agentes do Estado corruptos, implicando custos indesejados e desestímulo ao investimento. Reformas jurídicas e institucionais são fundamentais para esse processo. Tal qual uma legislação protetora dos direitos de propriedade intelectual, exemplo mencionado no início do texto, a criação

8 A promoção de grandes eventos esportivos como a Copa do Mundo de Futebol e as Olimpíadas pode ser uma ótima oportunidade para alavancar o ingresso de IED em um país. Contudo, em um cenário de corrupção generalizada, os recursos, tanto nacionais quanto estrangeiros, podem ser direcionados a obras economicamente ineficientes, como a construção de um luxuoso estádio público com custo de manutenção extremamente elevado. 
de um arcabouço jurídico anticorrupção composto de mecanismos preventivos e repressivos contribui para a formação desse ambiente institucional. Para WEI (2001, p. 05), uma reforma anticorrupção pode ser mais eficiente na atração de IED do que o oferecimento de incentivos fiscais excessivamente generosos que acarretam indesejáveis renúncias de receitas tributárias.

Até mesmo as economias que aparentemente estariam alheias às consequências das práticas corruptas começaram, nos últimos anos, a implementar programas governamentais anticorrupção, como é o caso da China, Rússia e Índia9 9 O Brasil, recentemente, realizou uma série de reformas institucionais que culminaram, por exemplo, na criação de uma agência governamental de controle da corrupção no âmbito federal (Controladoria Geral da União) ${ }^{10}$ e na divulgação dos gastos governamentais em sítios da internet ${ }^{11}$. Uma nova legislação está sendo preparada, com o foco na prevenção da corrupção nas atividades empresárias ${ }^{12}$. Isso demonstra a provável preocupação que existe em torno do fenômeno, especialmente no que diz respeito à necessidade de construção de um ambiente institucional livre de corrupção e consequentemente mais atraente para o investimento.

9 Nos últimos três anos, China, Rússia e Índia conduziram reformas legislativas com 0 objetivo de aperfeiçoar seus mecanismos de controle da corrupção. Tratam-se de projetos em andamento (BBC, 2010, 2012; RIA NOVOSTI, 2011).

10 Lei Federal $n^{0} 10.683$ de 28 de maio de 2003.

11 Lei Federal $n^{0} 12.527$ de 18 de novembro de 2011.

12 Projeto de Lei $n^{0} 6.826 / 2010$. A legislação prevê a possibilidade das empresas brasileiras serem punidas em caso de vinculação com práticas corruptas. A idéia é atacar os financiadores da corrupção. As empresas poderão ser impedidas de participarem de contratos do governo (a atual legislação é insuficiente nesse aspecto) e condenadas a severas multas. 
InterAção | 77

\section{CONSIDERAÇÕES FINAIS}

A dinâmica do mundo globalizado conduziu à competitividade das nações na atração do investimento estrangeiro direto. Os investidores, por sua vez, seguindo uma lógica de racionalidade econômica, enviam o seu capital para os locais que apresentem melhores possibilidades de retorno financeiro. Dessa maneira, somente as nações que demonstrarem qualidade em suas instituições, representada pela existência de um ambiente de estabilidade jurídica e política, poderão se beneficiar desse fluxo de investimentos.

O fenômeno da corrupção é, no entanto, a antítese do bom clima para proliferação do IED. Cogita-se, com esse estudo preliminar, que a percepção da corrupção em um determinado país pode ser fator condicionante para o ingresso de IED, baseando-se nos estudos realizados por Wei, Habib e Zurawicki.

Nesse contexto, a implementação de políticas anticorrupção pode ser uma opção interessante para incrementar a capacidade de atração de IED. Para isso, faz-se necessário o estabelecimento de reformas jurídicas e institucionais que demonstrem o comprometimento do país com o controle da corrupção. Indica-se a possibilidade de realização de estudos dessa natureza em outra oportunidade.

\section{REFERÊNCIAS}

AMAL, Mohamed; SEABRA, Fernando. Determinantes do Investimento Direto Externo (IDE) na América Latina: uma Perspectiva Institucional. EconomiA, Brasília, v. 8, n. 2, p. 231-247, 2007. 
78 | InterAção

ARNAUD. André-Jean. O Direito Entre Modernidade e

Globalização: lições de filosofia do direito e do Estado. Rio de Janeiro: Renovar, 1999.

ARRIGHI, Giovanni. O Longo Século XX: Dinheiro, Poder e as Origens de Nosso Tempo. Rio de Janeiro: Contraponto, 1998.

BÉNASSY-QUÉRÉ, A.; COUPET, M.; MAYER, T. Institutional Determinants of Foreign Direct Investment. World Economy, New Jersey, v. 30, n. 5, p. 764-782.

BRITISH BROADCASTING CORPORATION (BBC). China Expands Anti-corruption Law. 12.07.2011. Disponível em: <http:// www.bbc.co.uk/news/10595981 >. Acesso em: 05.08.2012.

Indian PM Singh appeals for anti-corruption

bill. 23.03.2012. Disponível em: <http://www.bbc.co.uk/news/worldasia-india-17484998>. Acesso em: 05.08.2012.

COOTER, Robert D.; SCHÄFER, Hans-Bernd. O Problema da Desconfiança Recíproca. The Latin American and Carribean Journal of Legal Studies, Berkeley, v. 1, n. 1, p. 01-19, 2006.

DAUDE, Christian; STEIN, Ernesto. The Quality of Institutions and Foreign Direct Investment. Economics \& Politics, Oxford, v. 19, n. 3, p. 317-344, 2007.

DUNNING, John H.; LUNDAN, Sarianna M. Multinational Enterprises and the Global Economy. 2. ed. Cheltenham: Edward Elgar Publishing, 2008.

GLOBERMAN, Steven; SHAPIRO, Daniel. Global Direct Investment Flows: The Role of Governance Infrastructure. World Development, Amsterdã, v. 30, n. 11, p. 1899-1919, 2002. 
HABIB, M.; ZURAWICKI, L. Country-level Investments and the Effect of Corruption. International Business Review, Amsterdã, v. 10, p. 687-700.

KAUFMANN, Daniel; KRAAL, A.; ZOIDO-LOBATÓN, P. Aggregating Governance Indicators. Policy Research Working Paper. New York, World Bank, 1999.

LI, Quan; RESNICK, Adam. Reversal of Fortunes: Democratic Institutions and Foreign Direct Investment Inflows to Developing Countries.

International Organizations, Cambridge, v. 57, p. 175-211, 2003.

MAURO, Paolo. Corruption and Growth. Quarterly Journal of Economics, Oxford, v. 110, n. 3, p. 681-712, 1995.

.The Effects of Corruption on Growth, Investment, and Government Expenditure: A Cross-Country Analysis. In: ELLIOTT, Kimberly Ann (org). Corruption and the Global Economy. Washington: Institute of International Economics, p. 83-107, 1997.

MUDAMBI, Ram; NAVARRA, Pietro. Institutions and International Business: a Theoretical Overview. International Business Review, Leiden, v. 11, p. 635-646, 2002.

NORTH, Douglass. Institutions. Journal of Economic Perspectives, Nashville, v. 5, n. 1, p. 97-112, 1991.

NUNNEMKAMP, Peter; SPATZ, Julius. Intellectual Property Rights and Foreign Direct Investment: a Disaggregated Analysis. Review of World Economics, Leibniz, v. 140, n. 3, p. 393-414, 2004.

ORGANISATION FOR ECONOMIC CO-OPERATION AND DEVELOPMENT. Foreign Direct Investment for Development: Maximising Benefits, Minimising Costs. Paris: OECD publications service, 2002. 
80 | InterAção

PRICEWATERHOUSECOOPERS. Confronting Corruption: The Business Case for an Effective Anti-corruption Programme (2008). Disponível em: <http://www.pwc.com/th/en/publications/com fronting-corruption.jhtml $>$. Acesso em: 10.12.2011.

RIA NOVOSTI. Russia Medvedev signs landmark anticorruption law. 04.05.2011. Disponível em: <http://en.rian.ru/ russia/20110504/163854280.html>. Acesso em 05.08.2012.

RICARDO, David. Princípios de Economia Política e Tributação. São Paulo: Nova Cultural, 1996.

ROSE-ACKERMAN, Susan. The Political Economy of Corruption. In: ELLIOTT, Kimberly Ann (org). Corruption and the Global Economy. Washington: Institute of International Economics, p. 31-60, 1997.

SHLEIFER, Andrei; VISHNY, Robert W. Corruption. The Quarterly Journal of Economics, Oxford, v. 108, n. 3, p. 599-617, 1993.

SMARZYNSKA JAVORCIK, B. The Composition of the Foreign Direct Investment and the Protection of Intellectual Property Rights: Evidence from Transition Economies. European Economic Review, Amsterdã, v. 48, p. 39-62, 2004.

SORNARAJAH, M. The International Law of Foreign Investment. 3. ed. Cambridge: Cambridge University Press, 2010.

TANZI, Vito. Corruption Around the World: Causes, Consequences, Scope and Cures. IMF Staff Papers, Washington, v. 45, n. 4, p. 559-594, 1998.

TRANSPARENCY INTERNATIONAL. Bribe Payers Index 2008. Berlim: Transparency International, 2008. 
. Relatório global de corrupção 2009: A

corrupção e o setor privado. Cambridge: Cambridge University Press, 2009.

UNITED NATIONS. World economic and social survey 2005:

financing for development. New York: United Nations publication, 2005.

WEI, Shang-Jin. Corruption and Globalization. Brooking policy brief series, n. 79, abr. 2001. Disponível em: <http://www.brookings.edu/ papers/2001/04corruption_wei.aspx >. Acesso em: 11.12.2011.

How Taxing is Corruption on International

Investors? The Review of Economics and Statistics, Massachusetts, v. 82, n. 1, p. 1-11, 2000a.

Negative alchemy? Corruption and Composition of Capital Flows. OECD development centre working paper, n. 165, 2000b. Disponível em: <http://www.oecd.org/ dataoecd/49/16/2072209.pdf>. Acesso em: 11.12.2011.

WEITZEL, Utz; BERNS, Sjors. Cross-border Takeovers, Corruption and Related Aspects of Governance. Tjalling C. Koopmans Research Institute Discussion Paper, n. 06-03, 2006. Disponível em: <http:// SSRN: http://ssrn.com/abstract=909546>. Acesso em 11.12.2011.

WORLD BANK. Helping Countries Combat Corruption: The Role of World Bank. Washington: World Bank, 1997.

WORLD COMISSION ON THE SOCIAL DIMENSION OF GLOBALIZATION. A fair globalization: creating opportunities for all. Genebra: International Labour Office, 2004. 
82 | InterAção 